\title{
Intestinal permeability in patients with coeliac disease and dermatitis herpetiformis
}

\author{
I BJARNASON, M N MARSH, A PRICE, A J LEVI, AND T J PETERS \\ From the Divisions of Clinical Sciences, Clinical, Cell Biology, and Section of Histopathology, MRC Clinical \\ Research Centre, Harrow, Middlesex and the University Department of Medicine, Hope Hospital (University \\ of Manchester School of Medicine), Eccles, Salford, United Kingdom.
}

SUMMARY Intestinal permeability was investigated in patients with coeliac disease and dermatitis herpetiformis by a ${ }^{51}$ Chromium-labelled ethylenediaminetetraacetate ( ${ }^{51} \mathrm{Cr}$-EDTA) absorption test and the results correlated with histomorphometric analysis and intraepithelial lymphocyte counts of jejunal biopsies. The mean $( \pm S D) 24$ hour urine excretion of ${ }^{51} \mathrm{Cr}$-EDTA in 34 healthy volunteers was $1.9 \pm 0.5 \%$ of the orally administered test dose. Patients with untreated coeliac disease (19) or untreated dermatitis herpetiformis (five) excreted significantly more ${ }^{51} \mathrm{Cr}$-EDTA than controls $(5.9 \pm 2.7 \%$ and $4.6 \pm 2 \cdot 1 \%$, respectively, $\mathrm{p}<0.001)$ and all were outside the normal range of $1 \cdot 0-2 \cdot 6 \%$. Patients with coeliac disease (42) treated for 6 months-23 years (mean 5 years) and patients with dermatitis herpetiformis (11) treated for 6 months -8 years (mean 3 years) excreted significantly more ${ }^{51} \mathrm{Cr}$-EDTA than controls, $4.2 \pm 2.4 \% \mathrm{p}<0.0001$ and $3.0 \pm 0.9 \%$ $\mathrm{p}<0.003$ respectively. Eleven of $14(79 \%)$ treated patients with coeliac disease with an entirely normal jejunal mucosae demonstrated abnormal intestinal permeability. Intestinal permeability did not correlate significantly with either the mucosal height/crypt depth ratio or intraepithelial lymphocyte counts in jenunal biopsies from patients with untreated or treated coeliac disease. The demonstration of a persistent increase in intestinal permeability in patients with both coeliac disease and dermatitis herpetiformis may suggest a common pathogenetic mechanism in both disorders. It is postulated that altered permeability may facilitate the entry of gluten or a fraction thereof into the lamina propria where it causes a cascade of immunological events.

Alterations in intestinal permeability may play an important role in the pathogenesis of some gastrointestinal disorders. ${ }^{1-5}$ Furthermore extraintestinal manifestations of certain conditions as a result of antigen antibody complex deposition, might be because of increased antigenic permeation through the intestinal mucosa. ${ }^{6-11}$ It is also conceivable that in the longer term increased permeability, by facilitating absorption of carcinogens or cocarcinogens, could potentiate the development of malignancy. 31213

Such possibilities remain largely speculative because of the lack of a reliable, sensitive method for assessing intestinal permeability in man. The potential value of such a procedure is not limited to the research laboratory, for if simple and of adequate

Address for correspondence: Dr I Bjarnason, Division of Clinical Sciences, MRC Clinical Research Centre, Watford Road, Harrow, Middlesex HA1 3UJ.

Received for publication 3 December 1984 sensitivity, could find clinical application as a screening procedure, or for assessing responses to therapy.

Recent reports describe the use of ${ }^{51} \mathrm{Cr}$-ethylenediaminetetraacetate $\left({ }^{51} \mathrm{Cr}\right.$-EDTA $)$ as a test probe of intestinal permeability both in vivo, ${ }^{15}$ and it appears to have many of the properties which is required of an inert marker. The results of one of the earlier studies showed that intestinal permeability remains raised in coeliac patients despite treatment with gluten free diet. ${ }^{14}$ We have now extended these observations to include a much larger group of untreated and treated coeliac patients and have compared these findings with a group of patients with untreated and treated dermatitis herpetiformis, also correlating changes in permeability with changes in the biopsy appearances of the jejunal mucosa.

Intestinal permeability is seen to be increased in both groups of patients and moreover persists 1214 
despite adequate treatment and responses to gluten restriction.

\section{Methods}

\section{SUBJECTS}

Thirty four apparently healthy volunteers $(20$ men, 14 women) of mean age 43 years (range: 18-74 years) made up the control group.

\section{COELIAC DISEASE}

There were 61 patients with coeliac disease (five men, 14 women, of mean age 45 years, range: $17-78$ years) of whom 19 were untreated: the remaining 42 patients (six men, 36 women, of mean age 53 years, range: 22-79 years) had been treated with a strict gluten free diet, implying exclusion of wheat, barley, rye, and oats for a mean period of five years (range: six months to 23 years).

Of these 61 patients, the diagnosis in 56 was based on a history of intestinal symptoms, evidence of anaemia or malabsorption together with a flat jejunal biopsy. Five individuals were relatives of known coeliac propositi and although asymptomatic, were found to have abnormal laboratory tests and an abnormal jejunal mucosa. All patients showed acceptable responses to gluten restriction, with loss of symptoms when present, improvement in nutritional status without the need of additional supplements, and improvements in the biopsy appearances. The ${ }^{51} \mathrm{Cr}$-EDTA test was carried out on each patient within a week of doing a jejunal biopsy.

\section{DERMATITIS HERPETIFORMIS}

A total of 16 patients with dermatitis herpetiformis was investigated, of which five (three men, two women, of mean age 36 years, range: $24-58$ years) were taking a normal diet. The remaining 11 patients (six men, five women, of mean age 49 years, range: $30-66$ years) had been treated with a gluten free diet for a mean of three years (range: six months to eight years) at the time of study. No patients had presented with significant malabsorption or nutritional deficiency and all but two were taking dapsone 50-200 mg daily. The majority of these patients were believed to be gluten sensitive as dietary indiscretions had regularly produced a flare up of the rash. Jejunal biopsy was undertaken on all but one of these patients before dietary gluten restriction commenced.

The diagnosis of dermatitis herpetiformis was based on the characteristic body distribution of intensely pruritic, erupting blisters together with the demonstration by immunofluorescence of $\operatorname{IgA}$ deposits within the papillary dermis of clinically uninvolved skin.

All subjects admitted to this study gave informed consent. The protocol for these investigations had also received approval by the local ethical committees appointed by the Harrow and Salford, District Health Authorities.

\section{HISTOLOGIC AND MORPHOMETRIC PROCEDURES}

Biopsies of the upper jejunal mucosa were carried out with a Watson capsule located fluoroscopically to the first loop of jejunum. After rapid retrieval, mucosal specimens were immediately spread out on thin card and fixed in either $10 \%$ buffered formaldehyde or Dalton's chrome-osmium fixing solution. The former specimens were routinely processed and embedded in paraffin and wax, sectioned at $3 \mu \mathrm{m}$ and stained with eosin and haemotoxylin. The latter were processed to epon, sectioned at 1 $\mu \mathrm{m}$ with glass knives and stained with $1 \%$ aqueous toluidine blue.

The number of intraepithelial lymphocytes was counted per 100 epithelial cell nuclei. Mucosal height (distance between muscular mucosae and tips of well oriented, vertically sectioned villi) and crypt depth (distance between basement membrane at base to the open 'mouth' of each crypt) were measured by interactive image analysis with a Joyce-Loebe magiscan as previously described. ${ }^{16}$

ABSORPTION OF ${ }^{51} \mathrm{Cr}$-EDTA

The test solution contained $100 \mu \mathrm{Ci}(3.7 \mathrm{mBq})$ of ${ }^{51} \mathrm{Cr}$-EDTA (specific activity $1-2 \mathrm{mCi} \mathrm{mg}^{-1} \mathrm{Cr}$, Amersham International, Code J13P) in $10 \mathrm{ml}$ distilled water. After an overnight fast, each subject drank the solution followed by approximately 300 $\mathrm{ml}$ water: food and fluids were allowed two hours later. Urine was collected during the ensuing 24 hours and analysed without knowledge of the diagnosis. Particular care was taken to ensure that no subject had recently ingested ethanol or was taking non-steroidal anti-inflammatory drugs both of which affect intestinal permeability.

${ }^{51} \mathrm{Cr}$-EDTA was analysed in urine by two methods initially, urine volumes were measured and a $5 \mathrm{ml}$ aliquot was counted for five minutes, in parallel with $5 \mathrm{ml}$ of a 1:500 dilution of the test solution, in a LKB Wallac 1280 gamma counter. ${ }^{14}$ The minimum detectable radioactivity was $0.03 \%$ of the administered dose per litre of urine. The second method, which is now routinely used, is simpler to perform. ${ }^{13}$ Samples of urine were collected directly into polyethylene bottles and made up to $2000 \mathrm{ml}$. A $1 \mathrm{ml}$ aliquot of the original test solution was also made up to $2 \mathrm{~L}$, and both counted in a highresolution bulk sample counter with two detectors set at maximum separation. The minimum detect- 
able radioactivity of the administered test dose was now less than $0.001 \%$ after counting for 100 seconds.

Results were expressed as a percentage of orally administered dose excreted in the urine per 24 hours.

\section{STATISTICS}

The urine excretion values from the patient groups showed a non-Gaussian distribution. The mean of the $\log _{10}$ transformed excretion values, however, differed significantly $\left(\mathrm{F}_{3,72}=5 \cdot 12, \mathrm{p}=0.003\right)$ by one way analysis of variance. The statistical difference between the groups was therefore analysed by the $t$-test on the logarithmically transformed data.

\section{Results}

CONTROL SUBJECTS

The percentage urinary excretion of radioactivity $\left({ }^{51} \mathrm{Cr}\right.$-EDTA $)$ per 24 hours in 34 healthy volunteers was $1 \cdot 0-2 \cdot 6 \%(\mathrm{M} \pm \mathrm{SD}: 1 \cdot 9 \pm 0 \cdot 5)$. (Fig. 1).

\section{COELIAC DISEASE PATIENTS}

The percentage 24 hour excretion for 19 untreated coeliac patients, $5 \cdot 9 \pm 2 \cdot 7 \%$ (range: $2 \cdot 7-14 \cdot 7 \%$ ), was significantly different from the control values $(\mathrm{p}<0.0001)$ (Fig. 1). There was no significant correlation between this index of permeability and malabsorption indices - for example, haemoglobin concentration, serum or red cell folate levels, serum iron, or faecal fat excretion. The lowest values for urinary radioactivity $(2.7 ; 2.8 ; 3.6 \%)$ were however seen in three of five asymptomatic coeliac patients.

For 42 treated coeliacs, the percentage 24 hour urinary excretion of $4 \cdot 2 \pm 2 \cdot 4 \%$ (range: $1 \cdot 3-12 \cdot 7 \%$ ) also differed significantly from that of controls $(p<0.0001)$ and of untreated coeliac patients $(p<0.001)$. The percentage excretion of radioactivity in $35(83 \%)$ of these patients exceeded the control range.

There was no significant correlation between the number of intraepithelial lymphocytes and percentage urinary excretion for either the untreated $(r=0.04: p>0.5)$ or treated $(r=0.25: p>0.05)$ patient groups (Fig. 2) nor between mucosal height/crypt depth and urinary radioactivity $(r=0.05: p>0.05$, $\mathrm{r}=0 \cdot 14: \mathrm{p}>0 \cdot 1$ ) for either group respectively (Fig. 3).

Despite the strict gluten abstention, mucosal morphology appeared 'normal' in only 19 of the 42 $(45 \%)$ treated coeliacs. The intraepithelial lymphocyte count was normal $(<40 / 100$ epithelial cell nuclei) in $21(50 \%)$ of the treated group. Combining both parameters, $14(33 \%)$ patients had entirely normal biopsies. Such patients had avoided gluten

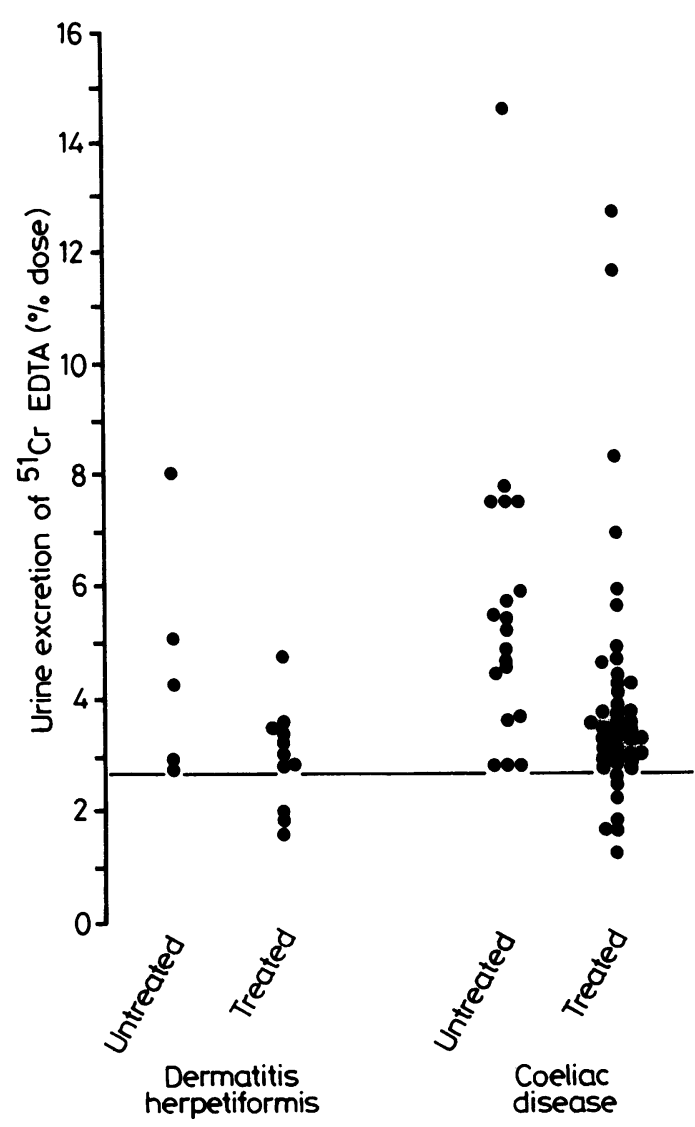

Fig. 1 Urinary excretion of ${ }^{51} \mathrm{Cr}$-EDTA. Each point represents one patient's 24 h urine excretion. Horizontal line indicates upper normal limit.

for at least five years yet 11 of these $14(79 \%)$ still showed increased absorption of the test probe.

\section{DERMATITIS HERPETIFORMIS PATIENTS}

The percentage 24 hour urinary excretion of ${ }^{51} \mathrm{Cr}$ EDTA in five patients on a normal diet, $4 \cdot 6 \pm 2 \cdot 1 \%$, was significantly different from that of controls $(\mathrm{p}<0.0001)$ and exceeded the normal range $(2 \cdot 7-8.0$ and $1 \cdot 0-2 \cdot 6 \%$, respectively). Jejunal morphology was abnormal in four of these untreated patients.

In 11 patients taking a gluten free diet, the 24 hour urinary excretion $3 \cdot 0 \pm 0 \cdot 9 \%$ (range: $1 \cdot 6-4 \cdot 8 \%$ ) differed significantly from that of controls $(p<0.0001)$ and untreated coeliac patients $(p<0.0001)$. Of these values, eight were clearly outside the control range (Fig. 1). Table 1 shows that before gluten restriction was started the histological findings in patients with dermatitis herpetiformis were often much less severe than those of 


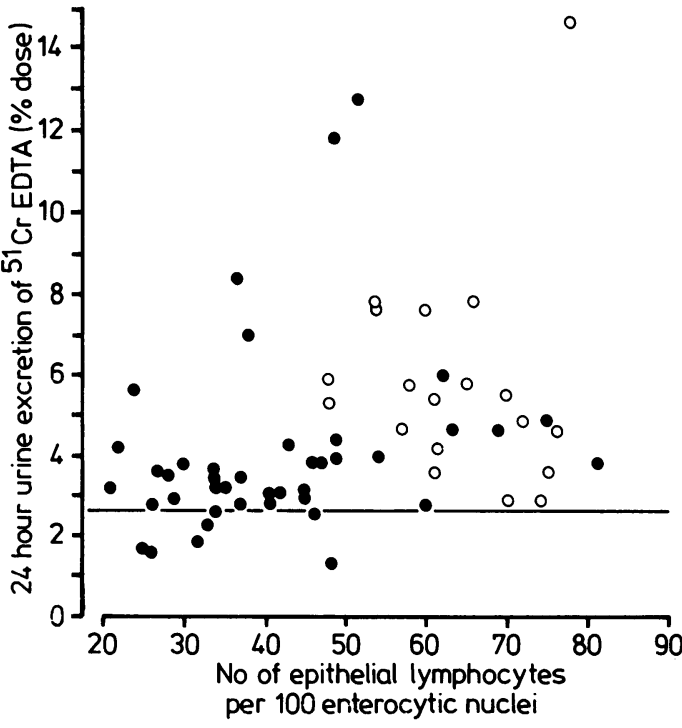

Fig. 2 Permeability vs intra-epithelial lymphocyte counts. Open circles: patients with untreated coeliac disease. Closed circles: patients with treated coeliac disease. Horizontal line indicates upper normal limit of the test. Number of intra-epithelial lymphocytes: Normal $<40 / 100$ enterocytes.

untreated patients with coeliac disease.

As jejunal biopsies were not undertaken when the ${ }^{51} \mathrm{Cr}$-EDTA was administered, no attempt was made to correlate permeability with mucosal struc-

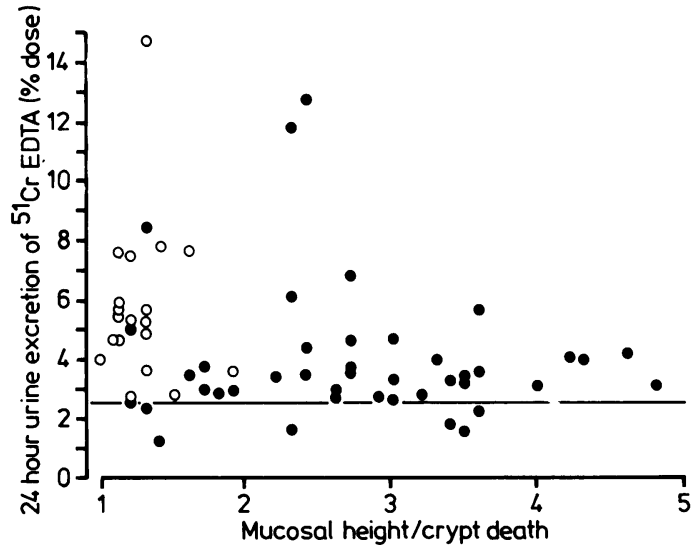

Fig. 3 Permeability vs mucosal height/crypt depth ratio. Symbols as in Fig. 2. Mucosal height/crypt depth: Normal $>2 \cdot 87$.

ture or epithelial lymphocyte densities.

\section{Discussion}

The results of this study extend our previous observations to show that intestinal permeability to a test dose of ${ }^{51} \mathrm{Cr}$-EDTA is markedly increased in patients with untreated coeliac disease, compared with the control group.

Secondly, this abnormality is seen to persist in the vast majority $(>75 \%)$ of patients on treatment with

Table Histological findings at the time of diagnosis, duration of treatment and permeability results in patients with dermatitis herpetiformis

\begin{tabular}{|c|c|c|c|c|}
\hline & $\begin{array}{l}\text { Duration of } \\
\text { treatment }\end{array}$ & $\begin{array}{l}\text { Mucosal height/ } \\
\text { crypt depth } \\
\text { ratio }\end{array}$ & $\begin{array}{l}\text { Lymphocytes/ } \\
\text { 100 enterocyte } \\
\text { nuclei }\end{array}$ & $\begin{array}{l}24 h^{51} C r-E D T A \\
\text { excretion (\%) }\end{array}$ \\
\hline Normal range & & $2 \cdot 87-6 \cdot 11$ & $<40$ & $1 \cdot 0-2 \cdot 6$ \\
\hline Patients with untreated $\mathrm{DH}$ & & $\begin{array}{l}1 \cdot 19 \\
1.24 \\
1.24 \\
1 \cdot 26 \\
4.38\end{array}$ & $\begin{array}{l}52 \\
27 \\
82 \\
72 \\
26\end{array}$ & $\begin{array}{l}8 \cdot 0 \\
2 \cdot 9 \\
2 \cdot 7 \\
5 \cdot 1 \\
4 \cdot 3\end{array}$ \\
\hline Patients with treated DH & $\begin{array}{l}6 \text { months } \\
6 \text { months } \\
6 \text { months } \\
21 / 2 \text { years } \\
3 \text { years } \\
3 \text { years } \\
31 / 2 \text { years } \\
4 \text { years } \\
4 \text { years } \\
6 \text { years } \\
7 \text { years }\end{array}$ & $\begin{array}{l}1.88 \\
2 \cdot 30 \\
* \\
1.73 \\
4.53 \\
1.42 \\
1.67 \\
1.43 \\
5.69 \\
1.48 \\
2.68\end{array}$ & $\begin{array}{l}42 \\
27 \\
* \\
42 \\
46 \\
50 \\
63 \\
56 \\
40 \\
50 \\
69\end{array}$ & $\begin{array}{l}3 \cdot 0 \\
3 \cdot 4 \\
1 \cdot 9 \\
3 \cdot 6 \\
2 \cdot 7 \\
3 \cdot 3 \\
3 \cdot 5 \\
2 \cdot 0 \\
1 \cdot 6 \\
2 \cdot 7 \\
4 \cdot 8\end{array}$ \\
\hline
\end{tabular}

* Not available for analyses but reported as 'subtotal villous atrophy'. 
a gluten free diet. In particular, this was so in 11 of 14 well treated coeliac patients in whom the jejunal mucosa was entirely normal by the objective criteria employed in this work.

Thirdly, permeability results showed little correlation with symptomatology or other indicators of mucosal disease - that is, haemoglobin concentration, nutritional deficiency, or degree of malabsorption.

Intestinal permeability has not been assessed previously in patients with dermatitis herpetiformis. Most of the patients studied were asymptomatic and histological examination revealed in many cases a much milder form of enteropathy compared with untreated coeliac patients, in agreement with other workers. ${ }^{17-19}$ Despite this their intestinal permeability appears to be increased to a similar extent to that in coeliac patients suggesting that the skin lesion is not because of increased permeation of gluten through the mucosa provided that ${ }^{51} \mathrm{Cr}$-EDTA and toxic gluten fractions share the same absorption pathway. It is difficult to explain why abnormal permeability to ${ }^{51} \mathrm{Cr}$-EDTA persists in the gluten sensitive subjects whose jejunal mucosae had returned to normal. Although patchiness of the upper intestinal lesion undoubtedly occurs, ${ }^{19}$ it was unlikely to have been relevant in the significant number of subjects treated for several years in whom increased permeability was shown in the presence of virtually normal mucosal structure. The second alternative is that inadvertant (or unavoidable) gluten ingestion influences intestinal permeability while not affecting villus/crypt morphology or epithelial lymphocyte densities. Thirdly, some other mechanism inducing mucosal permeability, and possibly triggered by trace amounts of ingested gluten, could occur by releasing factors from mucosal mast cells or other inflammatory cells within the lamina propria, as suggested elsewhere. ${ }^{20}$ While the conventional methods of tissue analysis employed in this study would fail to identify such effects, such possibilities cannot be dismissed. Conversely, if the means by which gluten or a subfraction thereof enters the mucosa is not due to a secondary inflammatory cascade, then our findings suggest the real possibility that a primary (?inherited) defect in intestinal permeability might be the mechanism that initially allows gluten access to the lamina propria. Only further studies will resolve this intriguing question.

Another observation is that our conclusions on the permeability alterations obtained in a very large series of treated coeliac patients differ sharply from those of a previous study with cellobiose/mannitol as permeability probes. $^{21}$ Thus while our patients treated on average for five years continued to show increased permeability to ${ }^{51} \mathrm{Cr}$-EDTA, other patients showed a return to a normal cellobiose/ mannitol urinary ratio within eight months of commencing a gluten free diet. Several reasons could explain this discrepancy: (i) that a high dose (5 $\mathrm{g}$ cellobiose) probably initiates both osmotic and increased transit effects, thereby effectively bypassing the diseased mucosal segment. Poorly absorbed solute, such as lactulose, certainly decreases the apparent permeability of rat intestine to ${ }^{51} \mathrm{Cr}$ EDTA $^{22}$ while others have shown that increases in the amount of poorly absorbed solute, such as mannitol, although maintaining isotonicity, greatly impair non-carrier-mediated transport of other luminal substances. ${ }^{23}$ (ii) cellobiose is partially hydrolysed by brush border oligosaccharidases ${ }^{21}$ and thus is an unsuitable marker in coeliac subjects in whom such enzymes are severely reduced compared with controls and recover only slowly with time. ${ }^{24}$ (iii) the test substances administered are hyperosmolar $(=1500 \mathrm{mmol} / \mathrm{l})$ containing large amounts $(20 \mathrm{~g})$ of sucrose and lactose $(20 \mathrm{~g})$. For the reasons advanced above, both additives would depress the urinary excretion of both cellobiose and mannitol.

Although ${ }^{51} \mathrm{Cr}$-EDTA is ideal in that it is completely non-metabolised ${ }^{25}$ and administered in trace amounts, there remains the theoretical objection that membrane integrity could be compromised by the $0.6-1.8 \mu \mathrm{mol}$ EDTA $^{26} 27$ (or Ca-EDTA ${ }^{28}{ }^{29}$ ) employed to stabilise the test probe. Against this is the observation that in experimental animals, a concentration of at least $250 \mathrm{mmol}$ EDTA is necessary before intestinal permeability becomes abnormal. ${ }^{26}{ }^{27}$ Additionally, the results of the ${ }^{51} \mathrm{Cr}$ EDTA absorption test closely resemble those of our in vitro studies where mucosal permeability was measured directly and independently of such variables as gastric emptying, intestinal transit and luminal dilutional factors. ${ }^{3} 1530$

In summary, we believe that the in vivo ${ }^{51} \mathrm{Cr}$ EDTA absorption test is a valid measure of intestinal permeability. In this study, it has been shown that patients with either untreated coeliac disease or dermatitis herpetiformis show abnormally permeable intestines to this probe marker. Furthermore, despite prolonged treatment with a gluten free diet for many years resulting in the jejunal mucosa returning to normal, a persisting, increased permeant state to this probe molecule appears to exist. The reason for this phenomenon is not clearly understood but may be relevant, either directly or secondarily, to the pathogenesis of these conditions.

Presented in part at the 85th Annual Meeting of the American Gastroenterological Association, New Orleans, Louisiana in May, 1984. 
References

1 Menzies IS. Absorption of intact oligosaccharide in health and disease. Biochem Soc Trans 1974; 2: 1042-7.

2 Warren S, Sommers SC. Pathology of regional ileitis and ulcerative colitis. JAMA 1954; 154: 189-93.

3 Menzies IS, Pounder R, Heyer S et al. Abnormal intestinal permeability to sugars in villous atrophy. Lancet 1979; 2: 1107-9.

4 Ukabam SO, Clamp JR, Cooper BT. Abnormal small intestinal permeability to sugars in patients with Crohn's disease of the ileum and colon. Clin Sci 1982; 62: 21-2P.

5 Walker WA. Antigen absorption from the small intestine and gastrointestinal disease. Pediatr Clin $N$ Am 1975; 22: 731-46.

6 Kern F. Extraintestinal complications. In: Kirsner JB, Shorter RG, eds. Inflammatory bowel disease. Philadelphia: Lea and Febiger, 1980: 217-40.

7 Jewell DP, Maclennan KP, Truelove SC. Circulating immune complexes in ulcerative colitis and Crohn's disease. Gut 1972; 13: 839-40.

8 Fiasse R, Lurhuma AZ, Cambiaso CL. Circulating immunecomplexes and disease activity in Crohn's disease. Gut 1978; 19: 611-7.

9 Wands JR, Lamont JT, Mann E, Isselbacher K. Arthritis associated with intestinal bypass procedure for morbid obesity. Complement activation and characer of circulating cryoprotein. N Engl J Med 1976; 294: 121-4.

10 Walker WA, Isselbacher KJ. Uptake and transport of macromolecules by the intestine. Possible role in clinical disorders. Gastroenterology 1974; 67: 531-50.

11 Atherton DJ. Allergy and atopic eczema II. Clin Exp Dermatol 1981; 6: 317-25.

12 Laker MF, Menzies IS. Increase in human intestinal permeability following ingestion of hypertonic solutions. J Physiol 1977; 265: 881-94.

13 Bjarnason I, Ward K, Peters TJ. The leaky gut of alcoholism: possible route of entry for toxic compounds. Lancet 1984; 1: 179-82.

14 Bjarnason I, Peters TJ, Veall N. A persistent defect in intestinal permeability in coeliac disease demonstrated by a ${ }^{51} \mathrm{Cr}$-labelled EDTA absorption test. Lancet 1983 ; 1: $323-5$.

15 Bjarnason I, Peters TJ. In vitro determination of intestinal permeability; demonstration of a persistent defect in coeliac disease. Gut 1984; 25: 145-50.

16 Slavin G, Sowter C, Robertson K, McDermott S,
Paton K. Measurement in jejunal biopsies by computer-aided microscopy. J Clin Pathol 1980; 33: 254-61.

17 Fry K, Keir P, McMinn AMH, Cowan JD, Hoffbrand AV. Small intestinal structure and function and haematological changes in dermatitis herpetiformis. Lancet 1967; 2: 729-34

18 Gawkrodger DJ, Blackwell JN, Gilmour HM et al. Dermatitis herpetiformis: diagnosis, diet and demography. Gut 1984; 25: 151-7.

19 Scott BB, Losowsky MS. Patchiness and duodenaljejunal variation of the mucosal abnormality in coeliac disease and dermatitis herpetiformis. Gut 1976; 17: 984-92.

20 Marsh MN. Immunocytes, enterocytes and the lamina propria: an immunopathological framework of coeliac disease. J R Coll Physicians (Lond) 1983; 14: 205-12.

21 Hamilton I, Cobden I, Rothwell J, Axon ATR. Intestinal permeability in coeliac disease. The response to gluten withdrawal and single dose gluten challenge. Gut 1982; 23: 202-10.

22 Bjarnason I, Smethurst P, Levi AJ, Peters TJ. Intestinal permeability to ${ }^{51} \mathrm{Cr}$-EDTA in rats with experimentally induced enteropathy. Gut 1985; 26: 579-85.

23 Catt SD, Menzies IS, Segal MB. The effect of poorly absorbed solute on human intestinal absorption. Proc Physiol Soc, J Physiol 1984; 349: 71P.

24 McNicholl B, Egan-Mithcell M, Stevens F et al. Mucosal recovery in treated childhood coeliac disease (Gluten sensitive enteropathy). J Pediatr 1976; 89: 418-24.

25 Lokken P. Studies on ${ }^{51} \mathrm{Cr}$-EDTA and its evaluation as a reference substance in gastrointestinal research. Norwegian Monographs in Medical Science. Oslo: Universitetsforlagett, 1970.

26 Tibdall CS. Magnesium and calcium as regulators of intestinal permeability. Am J Physiol 1964; 206: 243-6.

27 Ecknalier R, Buck B, Breitig D. An experimental model for measuring intestinal permeability. Digestion 1983; 26: 24-32.

28 Ahrens FA, Aronksi AL. A comparative study of the toxic effects of calcium and chromium chelates of ethylenediaminetetraacetate in the dog. Toxicol Appl Pharmacol 1970; 18: 10-25.

29 Aronson AL, Rogers KM. Effects of calcium and chromium chelates of ethylenediaminetetraacetate on intestinal permeability and collagen metabolism in the rat. Toxicol Appl Pharmacol 1972; 21: 440-53.

30 Bjarnason I, Goolamali SK, Levi AJ, Peters TJ. Intestinal permeability in atopic eczema. Br J Dermatol 1985; 112: 291-7. 